\title{
¿ESTAMOS TÉCNICAMENTE PREPARADOS PARA EL FLIPPED CLASSROOM? UN ANÁLISIS DE LAS COMPETENCIAS DIGITALES DE LOS PROFESORES EN ESPAÑA
}

\author{
Luis Alberto Andía Celaya \\ Universidad de Navarra \\ Raúl Santiago Campión \\ Jose Manuel Sota Eguizábal \\ Universidad de La Rioja
}

\begin{abstract}
RESUMEN: Se considera el modelo Flipped Classroom (FC) como una metaestrategia que puede aportar una estructura válida para la introducción de nuevas metodologías en las aulas. El objetivo de este estudio es el análisis del nivel de competencia digital del profesorado español y determinar su grado de preparación técnica para diseñar e implementar dicho modelo. Para ello se han utilizado dos herramientas: una encuesta diseñada de acuerdo a las recomendaciones del "Marco Común para la Competencia Digital del Profesorado" del Plan de Cultura Digital en la Escuela (ACDC cuestionario), que ha sido completada por más de 4.300 profesores de centros de educación infantil, primaria y secundaria españoles, y un cuestionario respondido por más de 100 expertos españoles en flipped learning para determinar, a través del cuestionario ACDC, cuáles serían las 12 competencias claves para el desarrollo adecuado del modelo FC. Este segundo análisis precisa las especificaciones técnicas requeridas por el modelo FC, y podría guiar al profesorado en la evaluación de sus competencias y en la construcción de itinerarios formativos en FC y TIC. En general, el profesorado español presenta niveles bajos o medio-bajos en muchas de las competencias claves para desarrollar este tipo de estrategias. Se pone de manifiesto la necesidad de un plan de mejora de la competencia digital docente que ayude a paliar las deficiencias detectadas.
\end{abstract}

PALABRAS CLAVE: aprendizaje activo, desarrollo profesional, destrezas digitales, clase invertida, metodología docente. 


\title{
"ARE YOU TECH-READY FOR FLIPPING?": AN ANALYSIS OF THE DIGITAL SKILLS OF SPANISH TEACHERS
}

\begin{abstract}
The Flipped Classroom Model (FC) can be considered as a meta-strategy that can provide an available structure in order to introduce the new methodologies in the classroom. The aim of this study is to analyze the level of digital competence of Spanish teachers and to determine if they are technically prepared to design and implement the model. For this, we used two tools. A survey designed according to the recommended dimensions of the "Common Framework for Digital Competence of Teachers" of the Digital Culture in School Plan (ACDC questionnaire). A questionnaire that we carried out among more than 100 Spanish experts in Flipped learning to determine, through analysis of the ACDC questionnaire, which would be the 12 key competences for the adequate development of the FC model. This second analysis will help us determine the technical specificities required by the FC model, which can guide the teachers in evaluating their own competences and in building a formative itinerary over FC and ICTs. The Spanish teachers have a low or medium-low level in many of the keys kills to include these strategies in their professional performance. A plan of improvement of digital skills is needed to alleviate the detected weaknesses.
\end{abstract}

KEYWORDS: Active learning, professional development, digital skills, Flipped classroom, teaching methodology.

Recibido: 03/07/2019

Aceptado: 25/09/2019

Correspondencia: Luis Alberto Andía Celaya, Universidad de Navarra, Facultad de Filosofía y Letras, Campus universitario, 31009 Pamplona, Navarra. Email: laandiac@gmail. com.

\section{INTRODUCCIÓN}

Desde 2002, la Comisión Europea, ha venido publicando una serie de informes titulados "Education and training Monitor" en los cuales se destacan aquellas prioridades en educación que contribuyen -o pueden contribuir-, a mejorar la integración, calidad y adecuación de los métodos de educación en Europa. Se incide de manera especial en la importancia de una formación acorde a las competencias necesarias en el siglo XXI y, específicamente, la necesidad de explotar las ventajas que ofrecen actualmente la tecnología y su correcta integración en las instituciones educativas (INTEF, 2017, p.5).

Esta propuesta a nivel europeo, además de describir las competencias que el alumnado debe desarrollar en la escuela, se centra en aquellas que los profesores de- 
berían incluir en sus prácticas para conseguir una mejor calidad educativa que tenga un impacto positivo en los estudiantes y en su desarrollo.

En 2006 la Comisión Europea reconoció como clave la competencia digital, y la definió de la siguiente manera: "La competencia digital entraña el uso seguro y crítico de las tecnologías de la sociedad de la información (TSI) para el trabajo, el ocio y la comunicación. Se sustenta en las competencias básicas en materia de TIC: el uso de ordenadores para obtener, evaluar, almacenar, producir, presentar e intercambiar información, y comunicarse y participar en redes de colaboración a través de Internet." (Parlamento y Consejo Europeo, 2006).

La competencia digital ya está incluida en la actual legislación española a través de la Ley Orgánica para la mejora de la Educación (LOMCE) de 2013, al mismo nivel que cualquier otra competencia a desarrollar y comparable por tanto con la lingüística, la matemática, la científica, la artística o la competencia social, por nombrar algunas de ellas. Por este motivo, resulta esencial que el profesorado utilice las Tecnologías de la Información y la Comunicación (TIC) como herramienta y como recurso metodológico en el proceso de enseñanza-aprendizaje. La incorporación y el desarrollo de las Tecnologías para el Aprendizaje y el Conocimiento darán forma, de manera progresiva, a la competencia/alfabetización digital de los docentes.

Uno de los principales objetivos que persigue el "Marco Estratégico de Educación y Formación" (ET2020) es asegurar una alta calidad en la docencia, para lo que propone la adaptación de la formación del profesorado a sus propios intereses, a la utilidad práctica y a las competencias necesarias. Para conseguir este objetivo, se sugiere la realización de una evaluación consistente a través de las dimensiones establecidas por el Marco Común para la Competencia Digital Docente (incluido en el Plan de Cultura Digital en la Escuela) que se aplicaría a las prácticas y requisitos de la enseñanza dentro del contexto del modelo Flipped Classroom.

El informe TALIS (2009) y la Encuesta Europea a centros escolares: Las TIC en Educación (2013) sugieren que los profesores españoles reciben el mayor número de horas de formación en TIC de Europa. Sin embargo, como se puede apreciar en las diferentes encuestas Ilevadas a cabo en los centros educativos, consideran que no están lo suficientemente preparados para integrar de forma plena los medios tecnológicos. "Paradoja que sugiere la necesidad de replantear la eficacia de una formación TIC poco orientada en general a la inmersión digital del docente y la apropiación didáctica de los nuevos medios." (Marco Común de Competencia Digital Docente, 2013).

García y García (2014) consideran que el progreso en términos de formación permanente en TIC (referida al uso real en los centros) no ha sido suficiente. "La inclusión o llegada masiva de tecnología al aula no ha significado una mejora para el aprendizaje de los estudiantes, además, después de las inversiones realizadas en los últimos años (70 millones de euros) (...), el uso para dotar a los centros con las infraestructuras necesarias para la integración de las TIC se ha encontrado como deficientes "(p. 37).

Es necesario, por lo tanto, integrar la formación en TIC para profesores en el proceso de enseñanza (Sánchez-García et al., 2013); una formación práctica que tome las herramientas tecnológicas como como herramientas docentes al servicio de me- 
todologías efectivas para el aprendizaje (Poyo, 2018). Sobre todo, la formación debe estar adaptada a las necesidades del profesorado de cada centro. La competencia digital (conocimiento habilidades, y actitudes) tiene que imbricarse en un proceso formativo, basado en modelos educativos que se centren en el aprendizaje y las metodologías activas y colaborativas.

Más allá de la existencia de teorías y estudios de investigación sobre los factores que influyen en el aprendizaje, para este equipo de autores y siguiendo la línea de Castillo y Cabrerizo (2005), es esencial el trabajo del profesor y su formación. "En un mundo con dinámicas de cambio tan aceleradas, con la aparición constante de nuevos conocimientos, con la incorporación de nuevas tecnologías y las mayores demandas de niveles de calidad en la enseñanza, es esencial que los docentes aprendan y se formen permanentemente" (p. 194). No hay duda de que el conocimiento ayuda a la promoción el desarrollo social, lo que coloca al profesorado en un lugar central y privilegiado (UNESCO, 1995, p. 125). Por lo tanto, cuanto más se adapte la praxis educativa a las nuevas costumbres y demandas sociales, mayor será la contribución social y de este modo "una mayor y mejor contribución del sistema educativo y la acción de los educadores a la construcción de la modernidad [...] significa un incremento en la calidad de la educación" (Toro, 1996, p. 6). El cambio social provocado por la extensión de las TOC exige una respuesta en el campo de pedagogía que debe ir hacia un modelo experiencial y creativo que supere las experiencias más receptivas y que fomente estrategias didácticas que permitan una integración de la tecnología en un aprendizaje más paidocéntrico. Entre estas está, como veremos más adelante, el modelo de clase invertida (Area, 2015, p. 40).

El estudio "Prácticas docentes y rendimiento estudiantil: evidencias desde PISA 2012 y TALIS 2013" identifica un conjunto de prácticas docentes concretas que a la vez que aumentan el rendimiento de los estudiantes en PISA, están relacionadas con la formación docente. "Encontramos un conjunto de medidas de eficacia mediaalta como que los profesores impartan las materias que han estudiado durante sus estudios preparatorios, que realicen cursos de formación inicial de profesorado, que realicen cursos de formación continua en orientación profesional de los alumnos o en técnicas de aprendizaje individualizado o que se incremente la cantidad de profesores que declara esforzarse para ayudar a sus alumnos a valorar el aprendizaje." (Méndez, 2015, p. 30).

En 2007, los profesores Bergmann y Sams iniciaron en Colorado una experiencia de grabación de vídeos con contenidos didácticos que pronto les llevó a definir un modelo pedagógico que se ha denominado Flipped Classroom o Flipped Learning ("clase invertida" en castellano) y que se basa, a grandes rasgos, en la atención personalizada al alumnado en clase mientras que el acceso a los contenidos queda garantizado por medios tecnológicos (Bergmann y Sams, 2012). Como apuntan Bergmann y Santiago (2018), el año 2014 el Flipped Learning Network definió Flipped Learning como un modelo pedagógico que transfiere la instrucción directa del espacio grupal al individual, convirtiendo el aula en un espacio de aprendizaje dinámico e interactivo, donde el profesor guía a los alumnos mientras éstos aplican lo que aprenden y se involucran en el objeto de estudio de forma creativa. El estudio progresivo del 
modelo y el propio establecimiento de iniciativas como el propio Flipped Learning Network han Ilevado a considerar este modelo como algo no estático, debido a la investigación de que es objeto, la innovación efectiva que genera en el aula y la rápida evolución tecnológica en que se apoya para su implementación. De esta manera se ha convertido en un movimiento global, que genera nuevas oportunidades y que se puede conceptualizar como una meta-estrategia que puede englobar a otras estrategias educativas (Bergmann y Santiago, 2018).

El modelo Flipped Classroom establece así una realidad flexible y dinámica donde se da prioridad al autoaprendizaje y a los procesos de reflexión. El alumno y el profesor son, por lo tanto, constructores activos de conocimiento: su propia experiencia les ayuda a entender y desarrollar este punto. En este marco, los profesores adquieren el rol de mediadores en los procesos de enseñanza-aprendizaje.

Las ventajas de este modelo no han sido avaladas de manera unánime por la literatura científica. Algunos autores opinan que la evidencia de la utilidad del modelo está aún por llegar (Goodwin y Miller, 2014). Es cierto que no hay un estudio concluyente sobre su eficacia, aunque sí se puede deducir, por medio de trabajos parciales basados la mayoría de ellos en la percepción de profesores y estudiantes (Martín y Santiago, 2015) o en estudios parciales comparativos donde se comparan resultados de la clase invertida con las de las metodologías más tradicionales (Mason et al., 2013; Blair et al., 2015). Otras investigaciones colaterales sobre la eficacia del aprendizaje a través del meta-análisis de los factores que influyen en este, como las de Hattie (2012), pueden aportar un refrendo indirecto a la línea didáctica impulsada por el modelo de clase invertida.

Además, hay que tener en cuenta que en muchas ocasiones se confunde o se mezclan en la realidad e incluso a nivel teórico los modelos blended y flipped learning (Marguleiux et al., 2014). Se describen metodologías mixtas donde la clase invertida se simplifica y mezcla con otro tipo de estrategias cuyo objetivo es conseguir un proceso más motivador para el alumnado y de mayor satisfacción para los docentes (Angelini y Carbonell, 2015), con lo que no es sencillo obtener una muestra lo suficientemente adecuada y amplia para realizar una medición fiable de los progresos de aprendizaje.

Otro de los factores de incidencia en este retraso en la definición de sus resultados podría estar relacionado con la constatación de que su implementación no resulta sencilla y necesita de una formación que abarca diferentes aspectos tanto pedagógicos como tecnológicos (Shi-Chun et al., 2014). Desde esta perspectiva, y en coherencia con la filosofía de su enfoque, la formación en Flipped Classroom debe estar alineada con las características del modelo.

Si nos atenemos a lo dicho hasta ahora, es evidente que la formación del profesorado en orden a su capacitación para aplicar estrategias de Flipped Learning debe ser amplia e integrada. Esto podría llevarnos a una reflexión extensa que desborda las pretensiones de este artículo. Uno de los modelos más conocidos en esta línea integradora es el TPACK definido en 2009 por Koehler y Mishra y que contempla tres campos de conocimiento en la tarea del docente: los contenidos la formación pe- 
dagógica y la formación tecnológica. Las relaciones entre las tres y las sinergias que producen son la base, de acuerdo con este modelo, de la eficacia de la tarea del profesorado. Por lo tanto serían las líneas de convergencia que pueden definirse como tecnológica comunicativa y contextual y la redefinición de los elementos emergentes como marcos teóricos, los que ayudan a la comprensión de los cambios que se derivan de la nueva sociedad digital (Sanabria y Cepeda, 2016).

Este es uno de los principales argumentos para proponer una evaluación inicial de la propia competencia digital (conocimiento, habilidades y utilidad o pragmatismo) de cara a llevar a cabo itinerarios de formación adaptados de la mejor manera posible. El conocimiento profesional se adquiere a través de la experiencia personal y del proceso de aprendizaje a largo plazo (aprendizaje continuo), que hace necesaria una oferta de formación de calidad para el profesorado. Perrenoud (2001, p. 510) propone diez criterios a los cuales debe responder la formación profesional y que citamos literalmente:

1. una transposición didáctica fundada en el análisis de las prácticas y de sus transformaciones,

2. un referencial de competencias que identifique los saberes y capacidades requeridos,

3. un plan de formación organizado en torno a competencias,

4. un aprendizaje a través de problemas, un procedimiento clínico,

5. una verdadera articulación entre teoría y práctica,

6. una organización modular y diferenciada,

7. una evaluación formativa fundada en el análisis del trabajo,

8. tiempos y dispositivos de integración y de movilización de lo adquirido,

9. una asociación negociada con los profesionales,

10.una selección de los saberes, favorable a su movilización en el trabajo.

Para cumplir con estos requisitos es necesario, en primer lugar, evaluar y definir de forma inicial y con la precisión debida, las competencias, conocimientos y actitudes que el profesor ya tiene antes de la formación en Flipped Classroom (Martín et al., 2016). Pérez Juste (2006) propone que el primer elemento clave cuando se diseña un programa (en este caso una formación), debe ser la identificación de necesidades.

Habitualmente, el procedimiento más obvio es la consulta a través de entrevistas o cuestionarios para responder a los requisitos fundamentales de validación de contenido. (Pérez Juste, 2006, p. 169).

\section{Material y métodos}

El objetivo de este estudio es comparar la percepción de los profesores y de los expertos en Flipped Classroom para evaluar el nivel de maestría requerido en las habilidades técnicas de Flipped Classroom dentro del grupo de profesores. 
Los cuestionarios (Anexos 1, cuestionario ACDC y 2, cuestionario para expertos) se presentan como la principal herramienta para obtener información sobre el objeto de estudio, dada su idoneidad a la hora de recoger datos de manera rápida y precisa. Su diseño ha sido llevado a cabo por los autores de este artículo. El proceso de selección de las dimensiones claves para su diseño y futura validación del instrumento se compone de las siguientes fases:

- Fase 1: Programación del grupo coordinador. El objeto del estudio está delimitado, así como las dimensiones del marco común y de la definición de competencia digital docente para profesorado no universitario. Los descriptores necesarios establecidos por la competencia digital docente han sido estudiados y, finalmente, también se han establecido los necesarios prerrequisitos en la formación en el modelo Flipped classroom. Las preguntas de evaluación están formuladas.

- Fase 2: Análisis y discusión de los ítems por el grupo coordinador. Las dimensiones indicadas por el marco común están agrupadas con las dimensiones propuestas por el documento, orientadas a la práctica docente. Se deciden las dimensiones y las relaciones entre indicadores e ítems. Se realiza un segundo borrador.

- Fase 3: El equipo debe ser consciente de su propia competencia y de la utilidad del ítem en la clase. El grupo coordinador revisa los ítems previos. A partir de ahí, se prepara un tercer borrador del cuestionario, adaptándolo a las categorías añadidas (objeto de este documento).

- Fase 4: Jueces y expertos externos de diferentes ramas del conocimiento validan la herramienta, en relación con su adecuación, relevancia y claridad. Esta será publicada en breve.

- Fase 5: De acuerdo con el análisis cualitativo y cuantitativo propuesto por los jueces y expertos, y una vez realizadas las oportunas modificaciones, se construye el instrumento final de evaluación.

- Fase 6: Primera fase piloto en una muestra pequeña de unos 50 profesores, para llevar a cabo un primer análisis de la validez y confianza de los ítems.

- Fase 7: Revisión de los ítems redactados, omisiones y nuevas contribuciones. Diseño final del cuestionario.

Para el diseño de los cuestionarios, las dimensiones establecidas por el Marco Común de Competencia Digital Docente (por el Plan de Cultura Digital en la Escuela MECD, p. 9) son las siguientes:

1. Información. Identificar, localizar, recuperar, almacenar, organizar y analizar información digital evaluando su finalidad y relevancia.

2. Comunicación y colaboración: comunicar en entornos digitales, compartir recursos a través de herramientas en línea, conectar y colaborar con otros a través de herramientas digitales, interactuar y participar en comunidades y redes; conciencia intercultural. 
3. Creación de contenido digital: crear y editar contenidos nuevos (textos, imágenes, videos...), integrar y reelaborar conocimientos y contenidos previos, realizar producciones artísticas, contenidos multimedia y programación informática, saber aplicar los derechos de propiedad intelectual y las licencias de uso.

4. Seguridad: protección personal, protección de datos, protección de la identidad digital, uso de seguridad, uso seguro y sostenible.

5. Resolución de problemas: identificar necesidades y recursos digitales, tomar decisiones a la hora de elegir la herramienta digital apropiada, acorde a la finalidad o necesidad, resolver problemas conceptuales a través de medios digitales, resolver problemas técnicos, uso creativo de la tecnología, actualizar la competencia propia y la de otros.

En este contexto debemos recordar que los objetivos de esta investigación son:

1. Analizar el nivel de competencia digital del profesorado español de acuerdo con el Marco Común de Competencia Digital del Profesorado establecido por el Ministerio de Educación de España y disponible en todas las lenguas oficiales del estado.

2. Analizar cuáles de los diferentes elementos de la encuesta están más directamente relacionados con el diseño y aplicación del modelo Flipped classroom.

3. Determinar si el profesorado encuestado tiene la preparación adecuada para el desarrollo del Aprendizaje Inverso.

4. Diseñar una propuesta de formación para mejorar, en caso de considerarse oportuno, las deficiencias detectadas.

\section{ANÁLISIS Y RESULTADOS}

En las siguientes secciones se analizan los datos recogidos para cada una de las áreas del Marco Común para la Competencia Digital Docente.

Para llevar a cabo el estudio, se ha realizado una encuesta entre expertos en Aprendizaje Inverso. El objetivo ha sido la identificación de los indicadores más relevantes del Cuestionario para el adecuado desarrollo del Aprendizaje Inverso en cada una de las áreas de competencia digital. En la citada encuesta, se pidió a los expertos que evaluaran dichos indicadores en una escala Likert de 4 valores. Para el cuestionario de expertos se han obtenido 78 respuestas válidas. Para cada eje se han seleccionado dos o tres indicadores de acuerdo al porcentaje y el número de veces en que ha sido escogido como óptimo. Los valores de la muestra se relación con los niveles del Marco Común de la siguiente forma:

$$
\mathrm{A} 1>1 ; \mathrm{A} 2>1,5 ; \mathrm{B} 1>2 ; \mathrm{B} 2>2,5, \mathrm{C} 1>3, \mathrm{C} 2>3,5
$$

Para el Cuestionario ACDC, se realizó un muestreo accidental entre profesores españoles de colegios de infantil, primaria y secundaria, por lo que en todo mo- 
mento los resultados se refieren a la muestra y no al conjunto de profesores. Se obtuvieron 4.399 respuestas válidas, que es una cantidad suficientemente grande para pensar que los resultados obtenidos pueden claramente indicativos de lo que ocurre en la realidad. Para cada área de competencia se procede al análisis de los datos obtenidos.

Tabla 1. Encuesta ACDC de profesores y expertos en Flipped Classroom

\begin{tabular}{|l|c|c|c|}
\hline \multicolumn{1}{|c|}{ Área } & $\begin{array}{c}\text { Promedio } \\
\text { expertos }\end{array}$ & $\begin{array}{c}\text { Promedio } \\
\text { profesores }\end{array}$ & p-valor \\
\hline 1. Información y alfabetización informacional & $2,74 \pm 0,70$ & $2,80 \pm 0,58$ & $\mathrm{p}<0,001$ \\
\hline 2. Comunicación y colaboración & $1,96 \pm 0,76$ & $2,80 \pm 0,64$ & $\mathrm{p}<0,001$ \\
\hline 3. Creación de contenido digital & $2,16 \pm 0,64$ & $1,86 \pm 0,52$ & $\mathrm{p}<0,001$ \\
\hline 4. Seguridad & $2,49 \pm 0,76$ & $2,05 \pm 0,62$ & $\mathrm{p}<0,001$ \\
\hline 5. Resolución de problemas & $2,35 \pm 0,67$ & $2,37 \pm 0,62$ & $\mathrm{p}<0,001$ \\
\hline
\end{tabular}

\section{ANÁlisis de las COMPETENCIAS DigitAleS}

\section{Área 1: Información y alfabetización informacional}

Descripción

Identificar, localizar, recuperar, almacenar, organizar y analizar información digital evaluando su finalidad y relevancia.

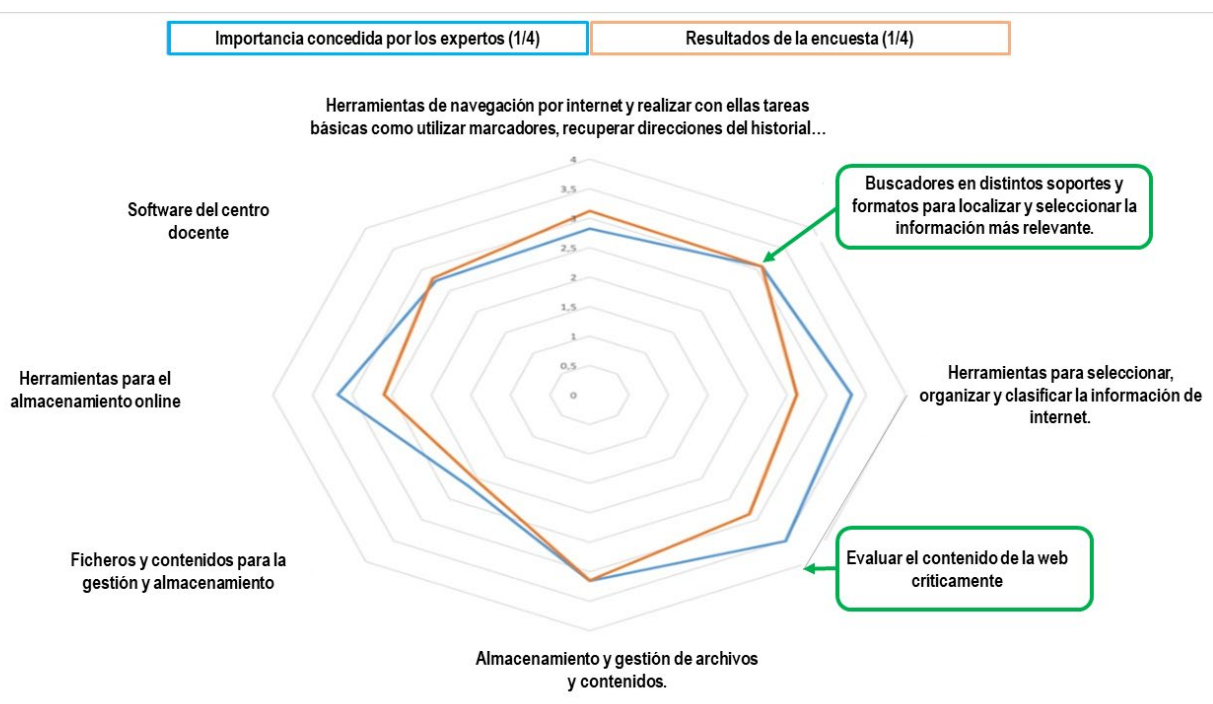

Figura 1. Gráfica del eje "Información y alfabetización informacional" 
De acuerdo con los resultados mostrados en la Figura 1, los indicadores elegidos por los expertos como los más relevantes para el Aprendizaje Inverso en el campo de la información son claramente los relacionados con la búsqueda y organización de información de calidad, con gran diferencia sobre el resto.

Los promedios se encuentran en valores que equivalen a un nivel medio-alto (B2) que indica que el profesorado posee un nivel intermedio en este eje. Sin embargo, es precisamente en los indicadores más útiles para el Aprendizaje Inverso, en los que encontramos resultados más débiles.

\section{Área 2: Comunicación y colaboración}

\section{Descripción}

Comunicar en entornos digitales, compartir recursos a través de herramientas en línea, conectar y colaborar con otros a través de herramientas digitales, interactuar y participar en comunidades y redes; conciencia intercultural.

En esta área se ha llevado a cabo un análisis similar, obteniendo los datos que se muestran en la Figura 2 donde se pueden comparar los resultados muestrales con los indicadores señalados para Aprendizaje Inverso, que son los indicadores relativos a la publicación en blog, wikis, etc., y a la elaboración de proyectos educativos colaborativos.

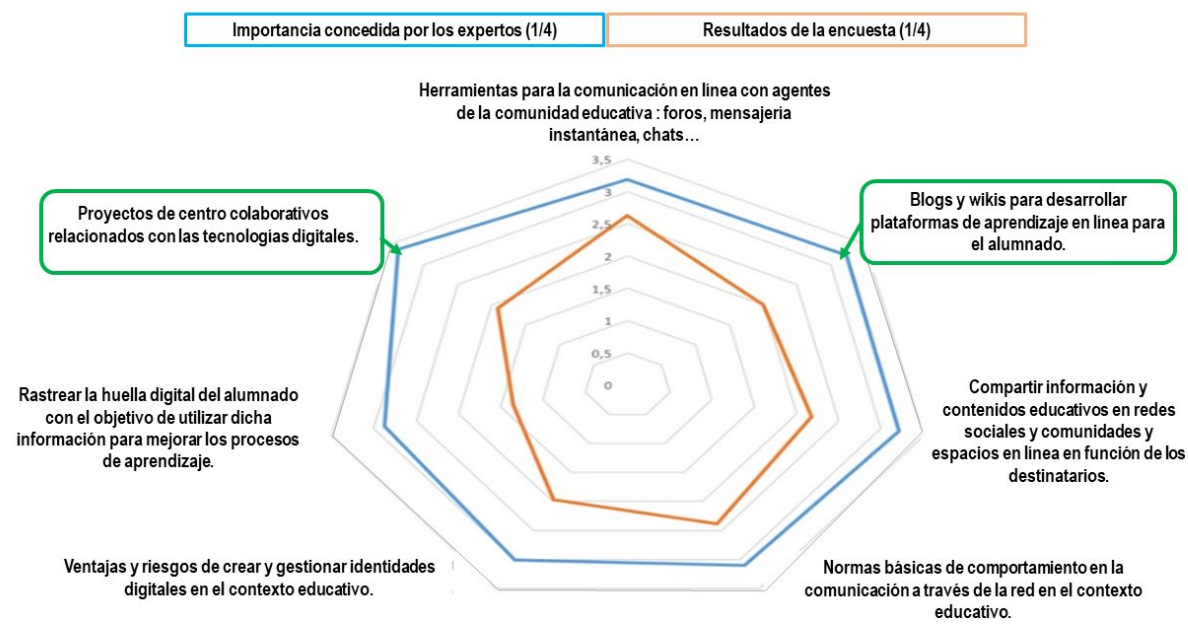

Figura 2. Gráfico del eje "Comunicación y colaboración"

En relación con el eje, podemos apreciar que el nivel del profesorado es bastante bajo, con la mitad de los valores por debajo de 2 y una dismetría relevante en cuanto a la distribución. Además de esto, los indicadores relevantes para el 
Aprendizaje Inverso muestran un nivel aún más bajo. Se puede concluir que este eje es uno de los que debería ser objeto de un mayor esfuerzo de mejora a través de formación.

\section{Área 3: Creación de contenido digital}

\section{Descripción}

Crear y editar contenidos nuevos (textos, imágenes, videos...), integrar y reelaborar conocimientos y contenidos previos, realizar producciones artísticas, contenidos multimedia y programación informática, saber aplicar los derechos de propiedad intelectual y las licencias de uso.

Siguiendo el mismo procedimiento, se analizan los datos del tercer eje. Al revisar los datos obtenidos, se establecen 3 indicadores relevantes para el Aprendizaje Inverso. En este caso los referidos a creación de vídeos didácticos, herramientas de elaboración de cuestionarios y herramientas para la gamificación del aprendizaje.

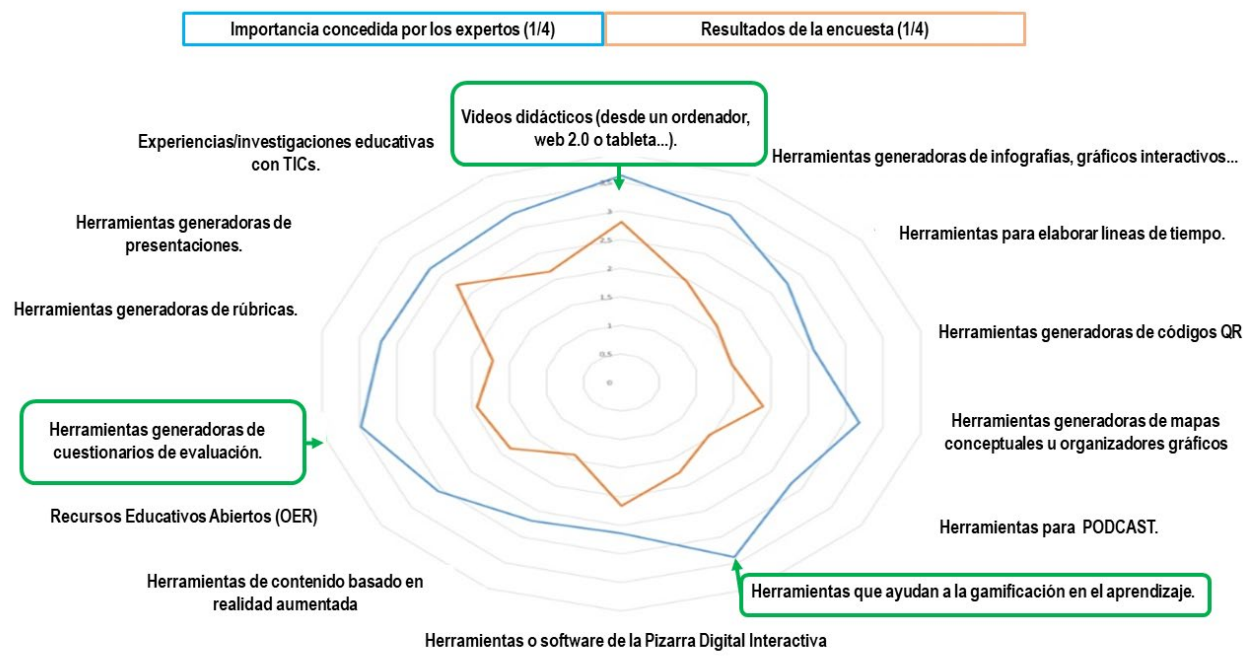

Figura 3. Gráfico del eje "Creación de Contenido Digital"

Atendiendo a los resultados, se puede observar una amplia dispersión entre los indicadores relevantes, que permanece bajo (B1 en el caso de los indicadores resaltados y A2 en el resto). Por primera vez, los datos específicos de Flipped muestran mejores niveles, que se identifican con el creciente uso de herramientas de vídeo en el campo de la docencia. A pesar de esto, el déficit en la utilización de los mismos queda también claramente reflejado en la gráfica. 


\section{Área 4: Seguridad}

\section{Descripción}

Protección personal, protección de datos, protección de la identidad digital, uso de seguridad, uso seguro y sostenible.

De nuevo, se analizan los datos del cuarto eje, estableciendo los indicadores relevantes para el Aprendizaje Inverso y revisando los datos obtenidos en relación con estos. Los resultados muestran que, una vez más, el nivel general del profesorado es medio-bajo (A2-B1). En este caso, los ítems relacionados con el Aprendizaje Inverso obtienen los mejores resultados. Quizá este sea uno de los ejes menos relevantes, dado que los ítems que incorpora son transversales, de manera independiente a la metodología utilizada en clase.

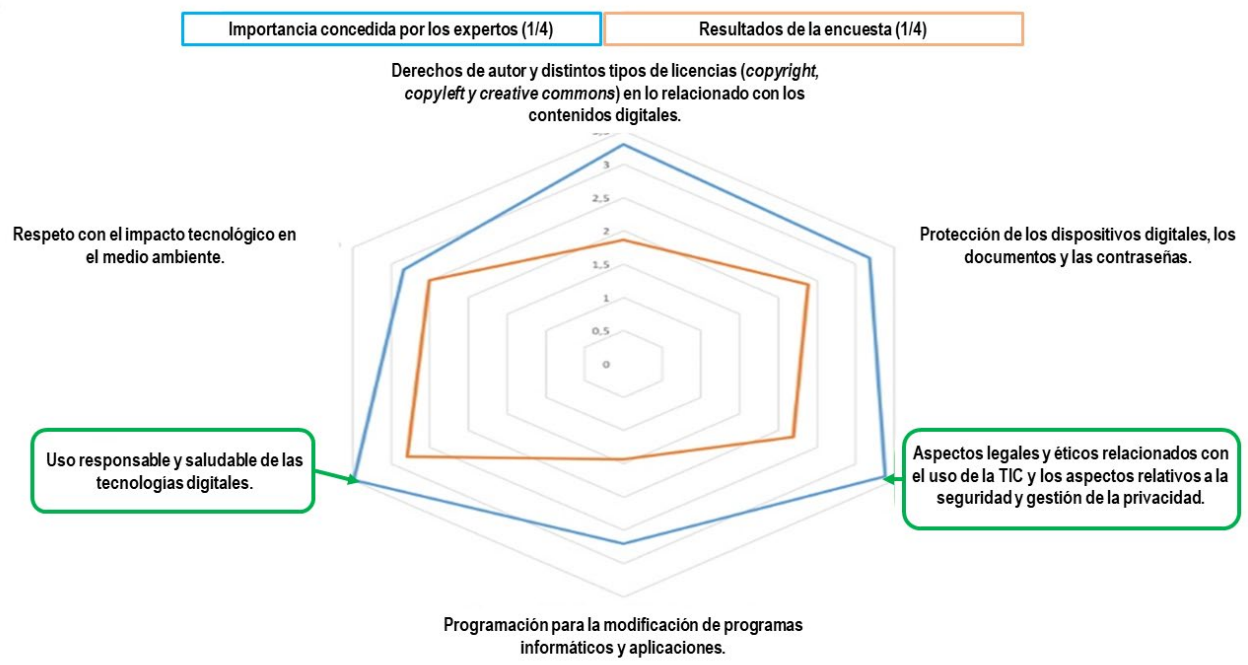

Figura 4. Gráfico del eje "Seguridad"

\section{Área 5: Resolución de problemas}

\section{Descripción}

Identificar necesidades y recursos digitales, tomar decisiones a la hora de elegir la herramienta digital apropiada, acorde a la finalidad o necesidad, resolver problemas conceptuales a través de medios digitales, resolver problemas técnicos, uso creativo de la tecnología, actualizar la competencia propia y la de otros.

Finalmente se analiza el último eje, se establecen tres indicadores relevantes para el Aprendizaje Inverso. En este caso, aunque solo se escogieron tres indicadores, los resultados muestran que los expertos distribuyeron sus respuestas de una manera mucho más amplia que en el resto de los ejes. 


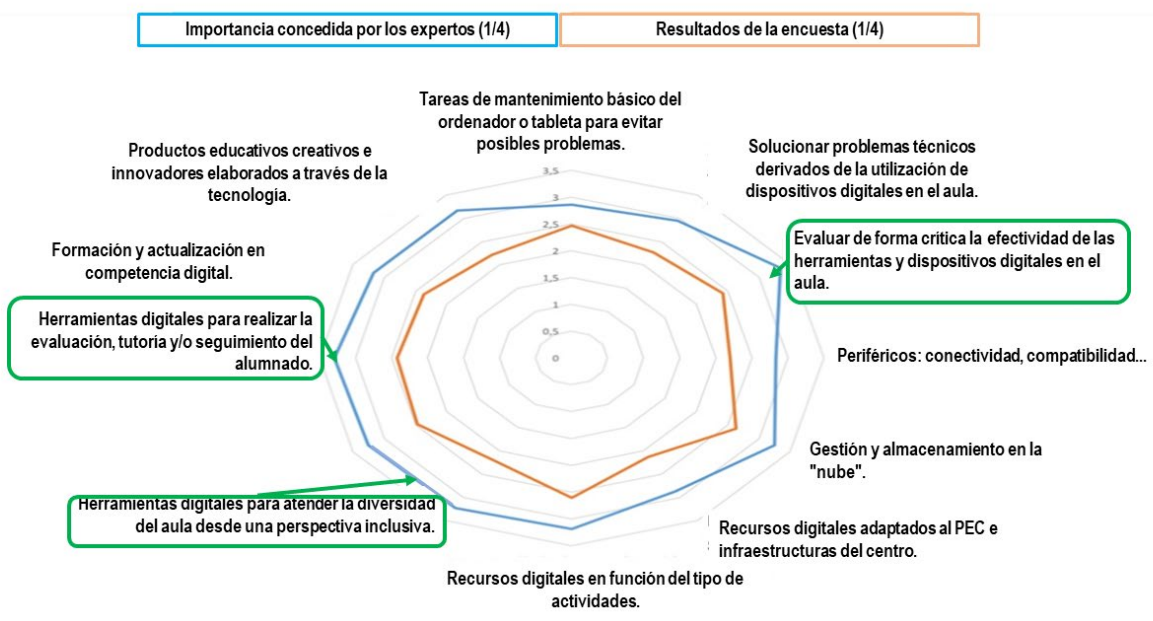

Figura 5. Gráfico del eje "Resolución de problemas"

De forma similar a lo ocurrido en los casos previos, el nivel general del profesorado en medio-bajo (B1). En esta ocasión, los ítems relacionados con el Aprendizaje Inverso obtienen peores resultados, aunque quizá no sean muy relevantes, dada la dispersión de elección de los expertos.

\section{DisCUSIÓN Y CONCLUSIONES}

El resultado de este trabajo nos permite presentar una herramienta destinada a la evaluación de las competencias digitales docentes. Nuestro objetivo es utilizarla como referencia para su diagnóstico, previo a la formación en Flipped Classroom. Por lo tanto, se ha creado una lista de ítems que corresponden a las dimensiones e indicadores establecidos por una serie de expertos. Incluimos el trabajo desarrollado en el Marco Común de Competencia Digital Docente, el Plan de Cultura Digital en la Escuela y el documento que define la competencia digital del profesorado no universitario.

Además, el cuestionario es rápido de responder y manejable en diferentes contextos, debido al uso de una misma escala Likert para todos los ítems, los cuales están agrupados en dimensiones, y al número de elementos propuestos.

Si bien existe en la literatura científica un gran número de cuestionarios de evaluación, este resulta en particular adecuado por su adaptabilidad. Por un lado, reúne los requerimientos de formación necesarios para dirigirse hacia el modelo Flipped Classroom y, por otro, proporciona la valoración de cada ítem, en relación con el grado en que el profesor se considera preparado para desarrollarlo y la frecuencia en que hace uso de él en su práctica docente. 
De esta forma se pueden identificar las fortalezas y debilidades de los docentes. Así mismo, se pueden establecer las bases para diseñar propuestas de formación para la mejora y el beneficio tanto de la práctica educativa como del desarrollo profesional docente.

Es cierto que todavía se debe validar y purificar este instrumento, por ejemplo, en la selección de aquellos ítems que, después de ser sometidos al juicio de los expertos desde diferentes sectores del campo educativo, son válidos para estudiar los indicadores propuestos. De esta manera se procedería a diseñar un instrumento más definitivo.

En relación con el área de información y alfabetización informacional, podemos destacar que los ítems seleccionados por los expertos son aquellos relacionados con la localización y organización de información de calidad, con gran diferencia sobre el resto. Estos ítems se sitúan en valores medios de 2,6 y 2,9 respectivamente, lo cual implica la posesión un nivel de conocimiento que puede ser interpretado simplemente como "adecuado".

Otra área importante en el análisis de la competencia digital y de la implementación del modelo de Aprendizaje Inverso es la de comunicación y colaboración. Presenta implicaciones directas con los dos momentos esenciales del Aprendizaje Inverso: "el espacio individual" (material que el estudiante recibe antes de la clase) y el" espacio grupal" donde son generados los espacios de colaboración e interacción entre el alumnado (Wallace, 2013).

En este sentido, los profesores expertos en Flipped indicaron como los aspectos más relevantes, por un lado, las "herramientas de comunicación como Blogs y Wikis" y, por otro lado, los "proyectos colaborativos relacionados con las TIC". En el primer caso, se podría evaluar el conocimiento del profesorado incluido en la muestra como "pasable" $(2,00)$, mientras que en el segundo no alcanzaría el valor mínimo aceptable. Este resultado nos proporciona un interesante punto de partida de cara a iniciar la implementación del modelo insistiendo en este tipo de habilidades, como por otro lado ya está siendo señalado desde hace algunos años (Barak, 2017).

Analicemos ahora el área de creación de contenido. Se considera esta área como la más importante para un diseño y desarrollo adecuado del modelo de clase inversa (Santiago et al., 2017). En este sentido, se puede afirmar que los cuatro ítems más destacados por el profesorado experto en Flipped son: "creación de vídeos didácticos" (en la línea del modelo tradicional de aprendizaje inverso), "gamificación y aprendizaje", el de "recursos educativos abiertos" y, finalmente, "herramientas para la creación de cuestionarios de evaluación". La importancia de estos campos ha sido descrita en un buen número de publicaciones científicas, de forma especial el ítem relacionado con el rol de la gamificación en el aprendizaje inverso (Zainuddin, 2018).

En referencia al conocimiento que el profesorado español posee de estos aspectos específicos, se puede afirmar que la primera de las secciones está situada en un valor que puede ser considerado "aceptable" $(2,81)$, mientras que las otras tres no exceden los valores de referencia medios $(1,75,1,85$ y 1,93 respectivamente). Teniendo en cuenta este conjunto de valores, podríamos entender que el profesorado carece de las competencias digitales para una adecuada implementación del modelo Flipped classroom (Hao and Lee, 2016). 
También se puede realizar una evaluación del área de Seguridad (Pires y Moreira, 2012). Estos ítems, sin estar directamente relacionados con Flipped classroom, representan elementos esenciales de competencia para garantizar el uso responsable y seguro de las tecnologías digitales (Shin, 2015). En este contexto podemos destacar que los dos aspectos subrayados por los expertos son "Aspectos legales y éticos relacionados con el uso de las TIC" y el "Uso responsable de las tecnologías digitales". El profesorado español parece "aprobar muy justo" en ambos indicadores.

Finalmente, analizaremos el área de competencia llamada resolución de problemas. En este apartado, los dos ítems que destacan son "Evaluación crítica de la efectividad de las herramientas digitales y los dispositivos en el aula" y "Formación y actualización en la competencia digital". Al igual que en el caso anterior, e profesorado español apenas supera por el mínimo los valores aceptables (2,4 y 2,2 respectivamente).

Se debe tener en cuenta que este análisis ha sido llevado a cabo teniendo en cuenta la percepción del profesorado y que esta suele exceder la realidad del nivel de competencia (Torres-Coronas y Vidal-Blasco, 2015). Esto nos lleva a pensar que los resultados podrían ser algo más bajos que los expresados por los profesores encuestados.

El análisis realizado nos Ileva a concluir que la competencia digital del profesorado español es muy mejorable, especialmente si tenemos en cuenta que la mayoría de los casos, aquellos profesores que responden al cuestionario tienden a presentar unas competencias superiores a aquellos que no lo hacen, y que, en términos generales, no poseen mínimamente las habilidades digitales aceptables para un adecuado diseño e implementación del modelo Flipped classroom. En este sentido, si tenemos en cuenta los 12 ítems seleccionados por los expertos, los más de 4000 profesores españoles encuestados reflejan una baja competencia en cuatro de ellos (los más importantes para el modelo) y una mínima competencia en el resto de los 8 analizados.

Uno de los elementos más importantes que afecta directamente a la competencia digital docente, es la revisión de las actitudes y de las relaciones internas y externas en escuelas y centros educativos (Comisión Europea, 2018).

Por tanto, a nivel interno, debe realizarse una promoción del aprendizaje conjunto y de la asunción compartida de responsabilidades. Externamente, es urgente la "desburocratización" de las relaciones institucionales para permitir un intercambio ágil y más eficaz en los procesos de asesoramiento.

En el plano de la formación, se precisa una línea más clara de desarrollo de las competencias digitales para el profesorado. Recientes estudios exigen que se progrese dentro de un contexto aplicado a la realidad docente, evitando incidir únicamente en el manejo técnico (Fernández et al., 2016, p. 228). En la actualidad no existen itinerarios de formación progresiva con la suficiente entidad para contribuir de manera relevante a paliar las deficiencias señaladas en este trabajo. Queda por lo tanto un importante camino que recorrer y que rebasa con creces la temática y extensión del presente estudio.

Sería necesario un estudio más extenso de la expansión del modelo de Aprendizaje Inverso en España a pesar de la falta de destrezas adecuadas por parte del profesorado (Uzunboylu y Karagozlu, 2017). Quizá la necesidad de un cambio en 
los aspectos metodológicos está realzando a este modelo como la estrategia más adecuada para promover una mejora real en el proceso de aprendizaje del alumnado.

\section{REFERENCIAS BIBLIOGRÁFICAS}

Amory, A. (2014). Tool-mediated authentic learning in an educational technology course: a designed-based innovation. Interactive Learning Environments, 22(4), 497-513. https://doi.org/10.1080/10494820.2012.682584.

Angelini, M. L. y García-Carbonell, A. (2015) "Percepciones sobre la integración de modelos pedagógicos en la formación del profesorado: la simulación y juego y el flipped classroom". Education in the Knowledge Society, 16(2), 16-30. http://doi. org/10.14201/eks20151621630.

Area, M. (2015) "Reconstruir el discurso pedagógico para la escuela de la sociedad digital", en J. de Pablos (Coord.), Los Centros Educativos ante el Desafío de las Tecnologías Digitales. Madrid: La Muralla.

Barak, M. (2017). Science Teacher Education in the Twenty-First Century: a Pedagogical Framework for Technology-Integrated Social Constructivism. Research in Science Education, 47, 283-303. http://doi.org/10.1007/s11165-015-9501-y.

Bergmann, J. y Sams, A. (2012). Flip Your Classroom: Reach Every Student in Every Class Every Day. Washington, DC: International Society for Technology in Education.

Blair, E., Maharaj, C. y Primus, S. (2015) "Performance and perception in the flipped classroom". Education and Information Technologies, 21(6), 1465-1482. http:// doi.org.10.1007/s10639-015-9393-5.

Camargo Abello, M., Calvo, G., Franco, C., Vergara, M., Londoño, M., Zapata, F. y Gravito, C. (2011). Las necesidades de formación permanente del docente. Educación y Educadores, 7, 79-112.

Campión, R. y Bergmann, J. (2018). Aprender al revés: Flipped Classroom 3.0 y Metodologías activas en el aula. Madrid: Paidós Educación.

Cardona Andújar, J. (2008). Formación y desarrollo profesional del docente en la sociedad del conocimiento. Madrid: Universitas.

Castillo, S. y Cabrerizo, J. (2005). Formación del profesorado en educación superior. Desarrollo curricular y evaluación. Madrid: McGrawHill.

European Comission (2018). European ideas for better learning: the governance of school education systems. The final report and thematic outputs of the ET2020 Working Groups Schools (2016-2018). Brussels: European Commission.

Fernández, J. C., Fernández M. C., Cebeiro, B. (2016) Competencias en TIC del profesorado en Galicia: variables que inciden en las necesidades formativas. Innovación educativa, 26, 215-231.

García, D. y García, E. (2014). Tecnologías y formación del profesorado, una visión crítica. Aula de innovación educative, 237, pp. 35-40. 
Goodwin, B. y Miller, K. (2014). "ResearchSays / Evidence on Flipped Classrooms Is Still Coming In". Technology-rich learning, 70(6), 78-80. Recuperado de http:// www.ascd.org/publications/educational-leadership/mar13/vol70/num06/Evidence-on-Flipped-Classrooms-Is-Still-Coming-In.aspx.

Hao, Y. y Lee, K. S. (2016) Teaching in flipped classrooms: Exploring pre-service teachers' concerns. Computers in Human Behavior, 57, 250-260.

Hattie, J. (2012). Visible learning for teachers. Maximizing impact on learning. London. Routledge.

INCAT (2015). Definición de la competencia Digital Docente para el profesorado no universitario de Cataluña aprobado por acuerdo de gobierno de la Generalitat en fecha 29 de diciembre de 2015 y pendiente de publicación en el DOGC. Recuperado de https://bit.ly/2BunyGl.

INTEF (2017). Marco Común de Competencia Digital Docente. MECD. Recuperado de https://bit.ly/2QqmwAw.

Koehler, M. y Mishra, P. (2009). What is Technological Pedagogical Content Knowledge (TPACK)? Contemporary Issues in Technology and Teacher Education, 9(1), 6070. Recuperado de https://www.learntechlib.org/primary/p/29544/.

Ley Orgánica para la mejora de la calidad educativa (LOMCE) 8/2013 de 9 de diciembre BOE.

Marco estratégico Educación y Formación 2020 (ET2020). Euridyce España. Recuperado de https://bit.ly/1QHaHnA.

Margulieux, L. E., Bujak, K. R., McCracken, W. M. y Majerich, D. M. (2014). "Hybrid, Blended, Flipped, and Inverted: Defining Terms in a Two Dimensional Taxonomy". Paper accepted to the 12th Annual Hawaii International Conference on Education, Honolulu, HI, January 5-9.

Martin, D. y Santiago, R. (2015). ¿Es el flipped classroom un modelo pedagógico eficaz?:Un estudio sobre la percepción de estudiantes de Primaria, ESO y Bachillerato. Comunicación y Pedagogía, Monográfico sobre Flipped Classroom, 285-286.

Martín, D., Sáenz, M. M., Santiago, R. y Chocarro, E. (2016). Diseño de un instrumento para evaluación diagnóstica de la competencia digital docente: formación flipped classroom. Didáctica, Innovación y Multimedia, 33. Recuperado de http:// dimglobal.net/revistaDIM33/docs/DIMAR33flipped.pdf.

Mason, G. S, Shuman, T. R. y Cook, K. E. (2013). Comparing the effectiveness of an inverted classroom to a traditional classroom in an upper-division engineering course. IEEE Transactions on Education, 56(4), 430-435.

Méndez Martínez, I. (2015). Prácticas Docentes y Rendimiento Estudiantil: Evidencia a partir de PISA 2012 y TALIS 2013. Fundación Santillana, Gobierno de La Rioja e Instituto Nacional de Evaluación Educativa.

Pérez Juste, R. (2006). Evaluación de programas educativos. Madrid: La muralla. 
Perrenoud, P. (2001). La formación de los docentes en el siglo XXI. Revista de Tecnología Educativa 14(3), 503-523. Recuperado de: https://bit.ly/2bwQCCX.

Pincas, A. (2003). Gradual and Simple Changes to incorporate ICT into the Classroom. Elearningeuropea.info. Recuperado de https://bit.ly/2GIMQ7N.

Pires, E. y Moreira, F. (2012). The Integration of Information and Communication Technology in Schools. Online Safety. Procedia Technology, 5, 59-66. http://doi. org/10.1016/j.protcy.2012.09.007.

Poyo, S. R. (2016). Transforming Teacher Preparation: Assessing Digital Learners' Needs for Instruction in Dual Learning Environments. Duquesne University, ProQuest Dissertations Publishing. Recuperado de https://bit.ly/2V5KI3g.

Recomendación del Parlamento Europeo y del Consejo de 18 de diciembre de 2006 sobre las competencias clave para el aprendizaje permanente (2006/962/CE). Recuperado de https://bit.ly/2GCMX4H.

San Nicolás, B., Fariña Vargas, E. y Area Moreira, M. (2012). Competencias digitales del profesorado y alumnado en el desarrollo de La docencia virtual. El caso de la Universidad de La Laguna. Revista Historia de la educación latinoamericana, 14, 227-245. http://doi.org/10.9757/Rhela.19.10.

Sanabria, A. L. y Cepeda, O., (2016). La educación para la competencia digital en los centros escolares: la ciudadanía digital. RELATEC. Revista Iberoamericana de Tecnología Educativa, 15(2), 95-112.

Sánchez-García, A-B., Mena, J. J., Guan Li, H. y Pinto, J. (2013). Teacher Development and ICT: The Effectiveness of a Training Program for In-service School Teachers. Procedia-Social and Behavioral Sciences, 92, 529-534. https://doi.org/10.1016/j. sbspro.2013.08.713.

Santiago, R., Díez, A. y Andía, L.A. (2017). 33 experiencias que ponen patas arriba el aprendizaje. Barcelona: UOC.

Santiago, R. (2014). Todo lo flipped es blended pero no todo lo blended es flipped. Recuperado de https://bit.ly/2SDCRXH.

Shi-Chun, D., Ze-Tian, F. y Yi, W. (2014). The Flipped Classroom Advantages and Challenges. Proceedings of the 2014 International Conference on Economic Management and Trade Cooperation. http://doi.org/10.2991/emtc-14.2014.3.

Shin, S.-K. (2015). Teaching critical, ethical, and safe use of ICT in preservice teacher education. Language Learning \& Technology, 19(1), 181-197. Recuperado de https://bit.ly/2liduGT.

TALIS (2009), OCDE. Estudio Internacional sobre la Enseñanza y el Aprendizaje. Informe Español. Recuperado de https://bit.ly/2DwfqWm.

Toro, J. B. (1996). El proyecto de nación y formación de los educadores en servicio. Santa Fé de Bogotá: Fundación Social Programa de comunicación social.

Torres-Coronas, T. y Vidal-Blasco, M-A. (2015). Students and employers perception 
about the development of digital skills in higher education. Revista de Educación. 366, 63-89. http://doi.org/10.4438/1988-592X-RE-2015-367-283.

Uzunboylu, H. y Karagözlü, D. (2017). La tendencia emergente aula invertida: Un análisis de contenidos de los artículos publicados entre 2010 y 2015. Revista de Educación a Distancia, 54. http://doi.org/10.6018/red/54/4.

Wallace, A. (2013) Social learning platforms and the flipped classroom. 2013 Second International Conference on E-Learning and E-Technologies in Education (ICEEE). 198-200.

Zainuddin, Z. (2018). Students' learning performance and perceived motivation in gamified flipped-class instruction. Computers \& Education, 126, 75-88. https:// doi.org/10.1016/j.compedu.2018.07.003. 


\section{AneXo 1}

\section{ACDCv2: Análisis Competencias Digitales Comunes (personalizado)}

Bienvenido al cuestionario ACDC

\section{Estimado profesor/a:}

El objetivo de la realización de este cuestionario es determinar su "nivel de Competencia Digital" con la idea de organizar los grupos y niveles necesarios cara a una posible formación sobre este tema. No le llevará más de 6 minutos.

Le aseguramos que todos los datos serán tratados de forma confidencial(tal y como indica la Ley Orgánica 3/2018, de 5 de diciembre, de Protección de Datos Personales y garantía de los derechos digitales); siendo el fin último del análisis exclusivamente académico.

Le pedimos su valoración sobre cada uno de los ítems siguiendo estos dos criterios: el Grado en el que usted se considera preparado para realizar o llevar a cabo el enunciado y el Grado en el que usted acostumbra a utilizar o realizar el recursol material en su práctica docente.

\section{A1 No lo conozco}

A2 Lo conozco pero no lo utilizo B1 Lo conozco y lo utilizo poco B2 Lo conozco y lo utilizo algo C1 Lo conozco y lo utilizo bastante C2 Lo conozco y lo utilizo mucho

\section{(C) Raúl Santiago, 2017, 2018 y 2019}

El presente código acredita que en el Registro de Propiedad intelectual de SAFE CREATIVE tuvo lugar con fecha 9 de agosto de 2016 a las 8:05 UTC la siguiente inscripción sobre la obra "ACDC: Analisis Competencias Digitales Comunes", registrada en SAFE CREATIVE con código 1608098600134. 
¿ESTAMOS TÉCNICAMENTE PREPARADOS PARA EL FLIPPED CLASSROOM? UN ANÁLISIS...

\section{ACDCv2: Análisis Competencias Digitales Comunes (personalizado)}

\section{Datos generales}

*1. Indique su sexo

Hombre $\bigcirc$ Mujer

\section{*2. Nombre y Apellidos}

*3. Edad, en años

* 4. Años de experiencia docente

* 5. Situación académica

Doctorado $\bigcirc$ Grado, Licenciatura $\bigcirc$ Diplomatura

Otro (especifique)

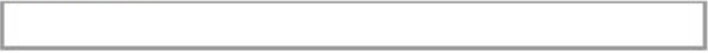

*6. Nivel educativo en el que desarrolla su trabajo

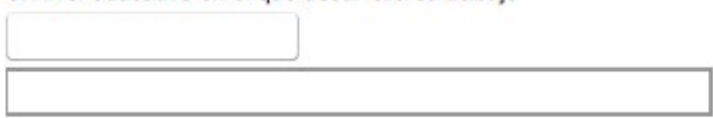

* 7. Nombre del centro

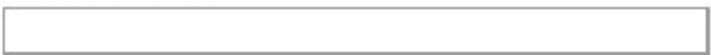




\section{ACDCv2: Análisis Competencias Digitales Comunes (personalizado)}

Información

Identificar, localizar, recuperar, almacenar, organizar y analizar la información digital, evaluando su finalidad y relevancia.

* 8. Información.
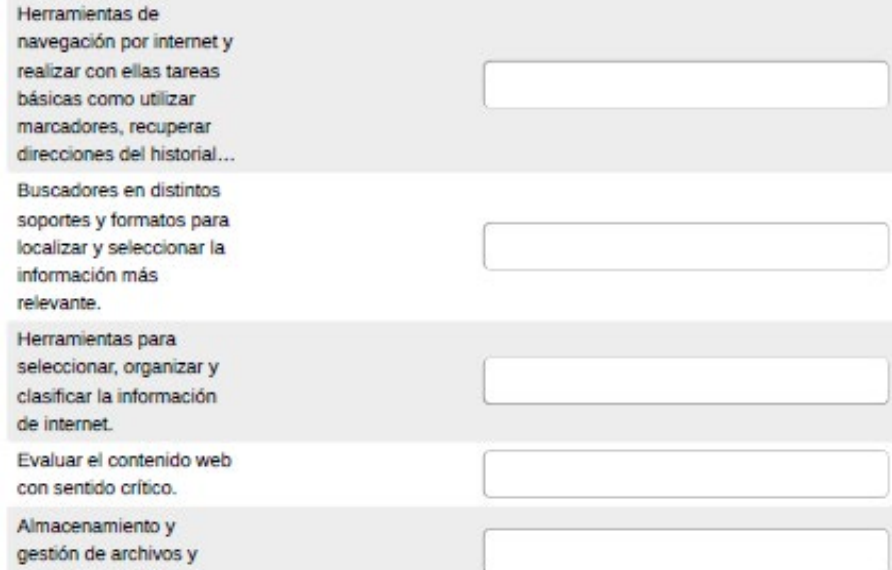


\section{ACDCV2: Análisis Competencias Digitales Comunes (personalizado)}

\section{Selección / Creación de contenidos}

Seleccionar, crear y editar contenidos nuevos (textos, imágenes, videos...), integrar y reelaborar conocimientos y contenidos previos, realizar producciones artísticas, contenidos multimedia y programación informática, saber aplicar los derechos de propiedad intelectual y las licencias de uso

* 9. Selección / creación de contenidos

Videos didácticos (desde un
ordenador, web 2.00
tableta...).
Herramientas generadoras
de intografias, gráficos
interactivos...
Herramientas para elaborar
lineas de tiempo.
Herramientas generadoras
de ódigos QR (Quick
Response).
Herramientas generadoras
de mapas conceptuales u
organizadores gráficos
Herramientas para
PODCAST.
Herramientas que ayudan a
la gamificación en el
aprendizaje.
Herramientas o sottware de
la Pizarra Digital Interactiva
Herramientas de contenido
basado en realidad
aumentada
Recursos Educativos
Abiertos (OER)
Herramientas generadoras
de cuestionarios de
evaluación.
Herramientas generadoras
de rúbricas.
Herramientas generadoras
de presentaciones.
Experiencias/investigaciones
educativas con TiCs.


ACDCv2: Análisis Competencias Digitales Comunes (personalizado)

Comunicación

Comunicar en entornos digitales, compartir recursos a través de herramientas en línea, conectar y colaborar con otros a través de herramientas digitales, interactuar y participar en comunidades y redes; conciencia intercultural.

*10. Comunicación.

Conocimiento y utilización

Herramientas para la

comunicación en línea

con agentes de la

comunidad educativa :

foros, mensajería

instantánea, chats..

Blogs y wikis para

desarrollar platatormas

de aprendizaje en línea

para el alumnado.

Compartir información y

contenidos educativos en

redes sociales y

comunidades y espacios

en línea en función de los

destinatarios.

Normas básicas de

comportamiento en la

comunicación a través de

la red en el contexto

educativo.

Ventajas y riesgos de

crear y gestionar

identidades digitales en

el contexto educativo.

Rastrear la huella digital

del alumnado con el

objetivo de utilizar dicha

información para mejorar

los procesos de

aprendizaje.

Proyectos de centro

colaborativos

relacionados con las

tencologias digitales. 


\section{ACDCv2: Análisis Competencias Digitales Comunes (personalizado)}

Seguridad

Protección personal, protección de datos, protección de la identidad digital, uso de seguridad, uso seguro y sostenible.

*11. Seguridad

Conocimiento y utilización

Derechos de autor $y$

distintos tipos de

licencias (copyright.

copyleft y creative

commons) en lo

relacionado con los

contenidos digitales.

Protección de los

dispositivos digitales, los

documentos y las

contrasenas.

Aspecto legales y éticos

relacionados con el uso

de la TiC y los aspectos

relativos a la seguridad y

getsión de la privacidad.

Programación para la

modificación de

programas intormáticos y

aplicaciones.

Uso responsable y

saludable de las

tecnologías digitales.

Respeto con el impacto

tecnolbgico en el medio

ambiente. 
LUIS ALBERTO ANDÍA CELAYA - RAÚL SANTIAGO CAMPIÓN - JOSE MANUEL SOTA EGUIZÁBAL

ACDCv2: Análisis Competencias Digitales Comunes (personalizado)

Resolución de problemas

Identificar necesidades y recursos digitales, tomar decisiones a la hora de elegir la herramienta digital apropiada, acorde a la finalidad o necesidad, resolver problemas conceptuales a través de medios digitales, resolver problemas técnicos, uso creativo de la tecnología, actualizar la competencia propia y la de otros. 
*12. Resolución de problemas.

Conocimiento y utilización

Tareas de mantenimiento

básico del ordenador 0

tableta para evitar

posibles problemas.

Solucionar problemas

técnicos derivados de la

utilización de dispositivos

digitales en el aula.

Evaluar de forma critica

la efectividad de las

herramientas $y$

dispositivos digitales en

el aula.

Periféricos: conectividad,

compatibilidad.

Gestion y

almacenamiento en la

"nube".

Recursos digitales

adaptados al PEC $e$

infraestructuras del

centro.

Recursos digitales en

función del tipo de

actividades.

Herramientas digitales

para atender la

diversidad del aula desde

una perspectiva

inclusiva

Herramientas digitales

para realizar la

evaluación, tutoría ylo

seguimiento de

alumnado.

Formación y

actualización en

competencia digital.

Actividades didácticas

para desarrollar en el

alumnado competencias

digitales.

Productos educativos

creativos e innovadores

elaborados a través de la

tecnología. 
LUIS ALBERTO ANDÍA CELAYA - RAÚL SANTIAGO CAMPIÓN - JOSE MANUEL SOTA EGUIZÁBAL

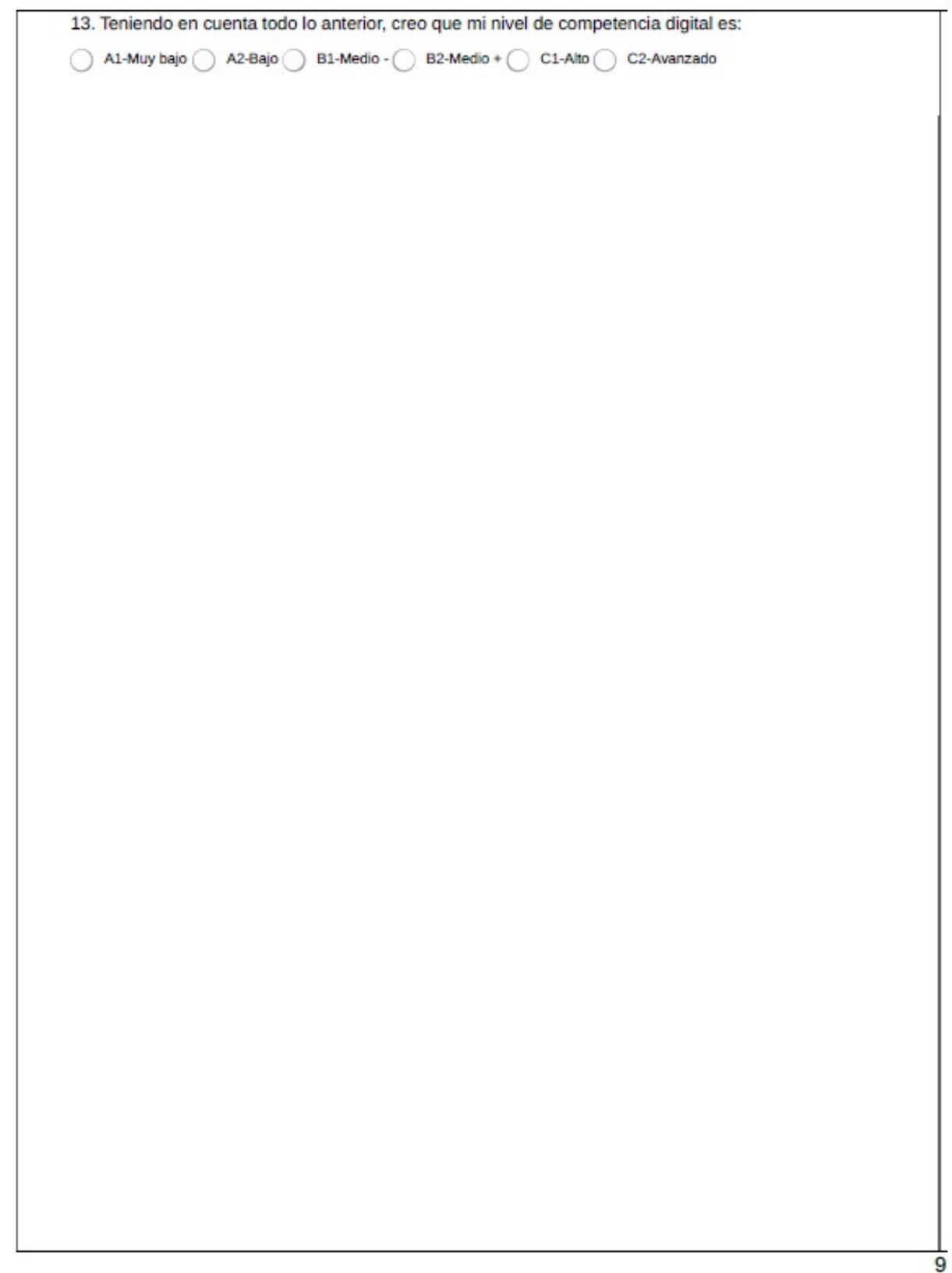




\section{Anexo 2}

Las Competencias Digitales Docentes y diseno y aplicación del Flipped Classroom

Selector de competencias para Flipped Classroom

Estimado colega, como sabes, hace unos meses diseñamos un cuestionario sobre Competencias Digitales. Se trata de una herramienta para determinar el nivel de los docentes en este importante tema y con objeto de mejorar todo lo relacionado con en trabajo docente en entornos digitales.

Como también sabes, uno de losenfoques pedagógicos mas en boga actualmente es el Flipped Classroom, modelo que persigue fundamentalmente la mejora de lacalidad del tiempo del estudiante en el aula, utilizando para ello, recursos y herramientas digitales.

Es por ello que, utilizando como base el cuestionario $A C D C$, nos gustaría profundizar en aquellas competencias mas relacionadas con el Flipped Learning. Te agradecería que tú, como conocedor y seguramente "usuario" del Flipped Learning, seleccionaras y valoraras aquellos items que te parecen mas relevantes para los docentes que se forman en este enfoque.

El trabajo es muy simple: valorar de 1 (valor mínimo) y $\mathbf{4}$ (valor máximo) la importancia que le concedes a cada uno de los items del cuestionario ACDC como elemento"clave" para hacer flipped classroom. Te rogaría que selecciones solo 2 de cada una de los cinco competenciasa las que des un valor máximo de 4 , salvo en la relacionada con selección y creación de contenido digital, en la que puedes seleccionar 4

Muchas gracias por tu valiosa contribución

(6) Raúl Santiago 2017 
LUIS ALBERTO ANDÍA CELAYA - RAÚL SANTIAGO CAMPIÓN - JOSE MANUEL SOTA EGUIZÁBAL

Las Competencias Digitales Docentes y diseño y aplicación del Flipped Classroom

\section{Datos generales}

-1. Indique su sexo

Hombre $\bigcirc$ Mujer

\section{-2. Edad, en años}

\section{- 3. Meses de experiencia en Flipped (Número aproximado)}

\section{-4. Situación académica}

Doctorado Grado, Licenciatura Diplomatura

Otro (especifique)

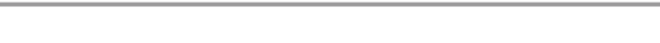

-5. Tipo de Centro
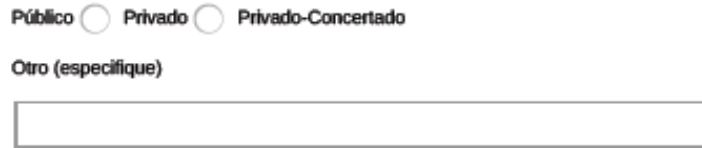

-6. Nivel educativo en el que desarrolla su trabajo

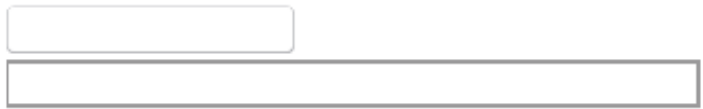




\section{Las Competencias Digitales Docentes y diseno y aplicación del Flipped Classroom}

\section{Información}

\section{Identificar, localizar, recuperar, almacenar, organizar y analizar la información digital, evaluando su} finalidad y relevancia.

* 7. Valora estas CCDD de acuerdo con su importancia para el desarrollo del Flipped Classroom(solo DOS COMO MUY IMPORTANTE)

\begin{tabular}{|c|c|c|c|c|}
\hline & Nada Importante & Poco Importante & Bastante Importante & Muy Importante \\
\hline $\begin{array}{l}\text { Herramientas de } \\
\text { navegación por internet } \\
\text { y realizar con ellas } \\
\text { tareas básicas como } \\
\text { utilizar marcadores, } \\
\text { recuperar direcciones } \\
\text { del historial... }\end{array}$ & & & & \\
\hline $\begin{array}{l}\text { Buscadores en distintos } \\
\text { soportes y formatos } \\
\text { para localizar y } \\
\text { seleccionar la } \\
\text { información más } \\
\text { relevante. }\end{array}$ & & & & \\
\hline $\begin{array}{l}\text { Herramientas para } \\
\text { seleccionar, organizar y } \\
\text { clasificar la información } \\
\text { de internet. }\end{array}$ & & & & \\
\hline $\begin{array}{l}\text { Evaluar el contenido } \\
\text { web con sentido crítico. }\end{array}$ & & & & \\
\hline $\begin{array}{l}\text { Almacenamiento y } \\
\text { gestión de archivos y } \\
\text { contenidos. }\end{array}$ & & & & \\
\hline $\begin{array}{l}\text { Herramientas para } \\
\text { recuperar archivos } \\
\text { eliminados. }\end{array}$ & & & & \\
\hline $\begin{array}{l}\text { Herramientas para el } \\
\text { almacenamiento de } \\
\text { archivos en línea. }\end{array}$ & & & & \\
\hline
\end{tabular}


LUIS ALBERTO ANDÍA CELAYA - RAÚL SANTIAGO CAMPIÓN - JOSE MANUEL SOTA EGUIZÁBAL

Las Competencias Digitales Docentes y diseño y aplicación del Flipped Classroom

Selección / Creación de contenidos

Seleccionar, crear y editar contenidos nuevos (textos, imágenes, videos...), integrar y reelaborar conocimientos y contenidos previos, realizar producciones artísticas, contenidos multimedia y programación informática, saber aplicar los derechos de propiedad intelectual y las licencias de uso 


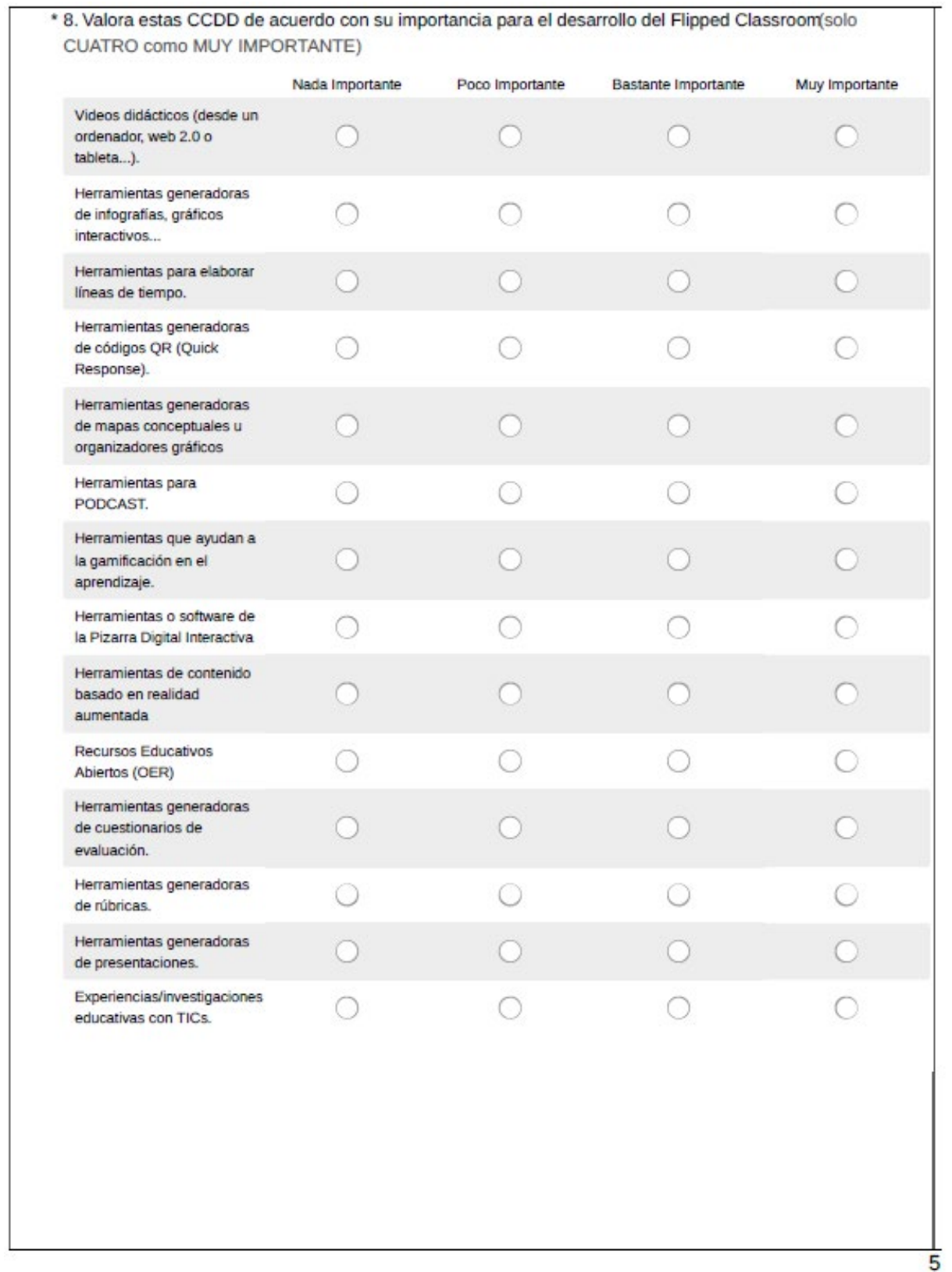


Las Competencias Digitales Docentes y diseño y aplicación del Flipped Classroom

\section{Comunicación}

Comunicar en entornos digitales, compartir recursos a través de herramientas en línea, conectar y colaborar con otros a través de herramientas digitales, interactuar y participar en comunidades y redes; conciencia intercultural.

* 9. Valora estas CCDD de acuerdo con su importancia para el desarrollo del Flipped Classroom(solo DOS como MUY IMPORTANTE)

Nada Importante

Poco Importante

Bastante Importante

Muy Importante

Herramientas para la

comunicación en línea

con agentes de la

comunidad educativa :

foros, mensajería

instantánea, chats...

Blogs y wikis para

desarrollar platatormas

de aprendizaje en línea

para el alumnado.

Compartir información y

contenidos educativos

en redes sociales y

comunidades y espacios

en línea en función de

los destinatarios.

Normas básicas de

comportamiento en la

comunicación a través

de la red en el contexto

educativo.

Ventajas y riesgos de

crear y gestionar

identidades digitales en

el contexto educativo.

Rastrear la huella digital

del alumnado con $\mathrm{el}$

objetivo de utilizar dicha

informaciōn para

mejorar los procesos de

aprendizaje

Proyectos de centro

colaborativos

relacionados con las

tencologías digitales. 
¿ESTAMOS TÉCNICAMENTE PREPARADOS PARA EL FLIPPED CLASSROOM? UN ANÁLISIS...

Las Competencias Digitales Docentes y diseño y aplicación del Flipped Classroom

Seguridad

Protección personal, protección de datos, protección de la identidad digital, uso de seguridad, uso seguro y sostenible.

* 10. Valora estas CCDD de acuerdo con su importancia para el desarrollo del Flipped Classroom(solo DOS como MUY IMPORTANTE)

Derechos de autory
distintos tipos de
licencias (copyright,
copyleft y creative
commons) en lo
relacionado con los
contenidos digitales.
Protección de los
dispositivos digitales, los
documentos y las
contrasentas.
Aspecto legales y étioos
relacionados con el uso
de la tic y los aspectos
relativos a la seguridad y
getsión de la privacidad.
Programaciónte importante
modificación de la
programas intormáticos
y aplicaciones.
Uso responsable y
saludable de las
tecnologías digitales.
Respeto con el impacto
tecnológico en ei medio
ambiente.


Resolución de problemas

Identificar necesidades y recursos digitales, tomar decisiones a la hora de elegir la herramienta digital apropiada, acorde a la finalidad o necesidad, resolver problemas conceptuales a través de medios digitales, resolver problemas técnicos, uso creativo de la tecnología, actualizar la competencia propia y la de otros.

* 11. Valora estas CCDD de acuerdo con su importancia para el desarrollo del Flipped Classroom(solo DOS COMO MUY IMPORTANTE)

\begin{tabular}{|c|c|c|c|c|}
\hline & Nada importante & Poco importante & Bastante importante & Muy importante \\
\hline $\begin{array}{l}\text { Tareas de } \\
\text { mantenimiento básico } \\
\text { del ordenador o tableta } \\
\text { para evitar posibles } \\
\text { problemas. }\end{array}$ & & & & \\
\hline $\begin{array}{l}\text { Solucionar problemas } \\
\text { técnicos derivados de la } \\
\text { utilización de } \\
\text { dispositivos digitales en } \\
\text { el aula. }\end{array}$ & & & & \\
\hline $\begin{array}{l}\text { Evaluar de forma critica } \\
\text { la efectividad de las } \\
\text { herramientas y } \\
\text { dispositivos digitales en } \\
\text { el aula. }\end{array}$ & & & & \\
\hline $\begin{array}{l}\text { Periféricos: } \\
\text { conectividad, } \\
\text { compatibilidad... }\end{array}$ & & & & ) \\
\hline $\begin{array}{l}\text { Gestión y } \\
\text { almacenamiento en la } \\
\text { "nube". }\end{array}$ & & & & \\
\hline $\begin{array}{l}\text { Recursos digitales } \\
\text { adaptados al PEC e } \\
\text { infraestructuras del } \\
\text { centro. }\end{array}$ & & & & \\
\hline $\begin{array}{l}\text { Recursos digitales en } \\
\text { función del tipo de } \\
\text { actividades. }\end{array}$ & & & & \\
\hline $\begin{array}{l}\text { Herramientas digitales } \\
\text { para atender la } \\
\text { diversidad del aula } \\
\text { desde una perspectiva } \\
\text { inclusiva. }\end{array}$ & & & & \\
\hline
\end{tabular}


¿ESTAMOS TÉCNICAMENTE PREPARADOS PARA EL FLIPPED CLASSROOM? UN ANÁLISIS...

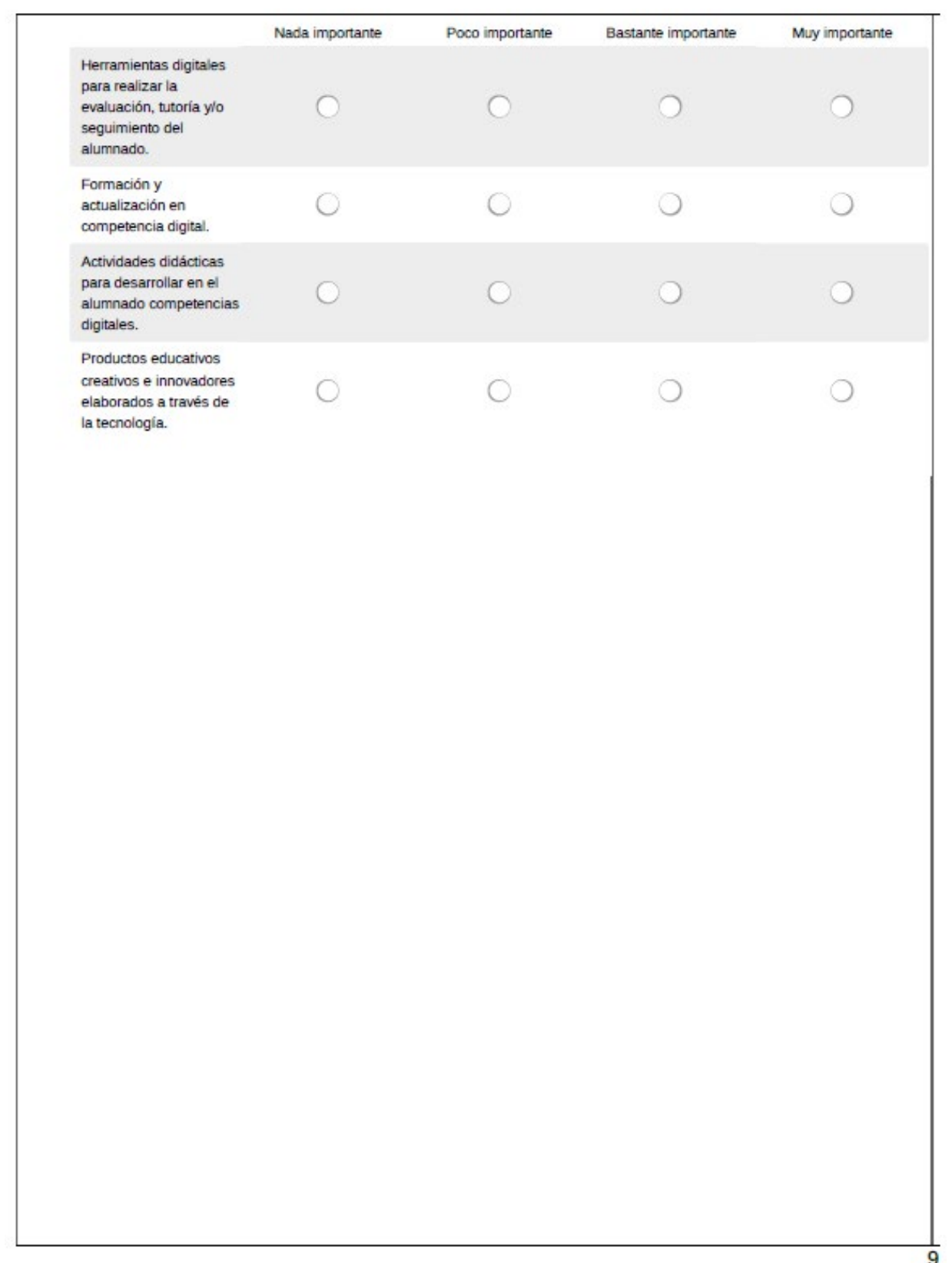

